\title{
Faz Değiștiren Madde Olarak Nano Katkılı Stearik Asit ve Palmitik Asidin Termofiziksel Özelliklerinin İncelenmesi
}

\author{
Taylan Gazi ÜREGEN ${ }^{*}$, Gamzepelin AKSOY ${ }^{2}$, Ahmet KOCA ${ }^{3}$ \\ ${ }^{1}$ Mekatronik Mühendisliği Bölümü, Firat Üniversitesi, Elazı̆̆ , Türkiye \\ ${ }^{2}$ Yazılım Mühendisliği Bölümü, Fırat Üniversitesi, Elazığ, Türkiye \\ ${ }^{3}$ Mekatronik Mühendisliği Bölümü, Fırat Üniversitesi, Elazığ, Türkiye \\ *1 tguregen@gmail.com, ${ }^{2}$ gamzepelina@gmail.com, ${ }^{3}$ dr.koca.ahmet@gmail.com
}

(Geliş/Received: 20/02/2019;

Kabul/Accepted: 29/04/2019)

Öz: Günümüzde faz değiştiren maddeler 1sı depolama sistemlerindeki mühendislik uygulamalarında yaygın olarak kullanılmaktadır. Bu maddeler, 1s1 sistemlerde, 1s1l enerji depolama elemanı olarak tercih edilirler. Is1 depolama sistemlerinin geliştirilebilmesi için, faz değiştiren maddelerin seçimi isı transfer mekanizmasına ek olarak önemli bir rol oynamaktadır. Faz değiştiren maddelerde nano parçacık katkısının termofiziksel özelliklerin iyileştirilmesinde önemli bir etkisi vardır. Bu çalışmada, faz değiştiren maddelerden olan Stearik asit ve Palmitik asit kimyasallarına ağırlıkça \%1, \%3, \%5, \%10 oranlarında Grafit nano parçacı̆̆ı eklenmiştir. Hazırlanan karışımların termofiziksel özellikleri belirlenmiştir. Hazırlanan homojen karıșımların, saf Stearik asit ve Palmitik aside göre ısıl iletkenlik değerlerinde artma, gizli 1sı değerlerinde azalma görülmüştür. En yüksek 1sıl iletkenlik artışı Stearik asit-\%5 Grafit karışımında \%89, Palmitik asit-\%10 Grafit karışımında ise \%64 olarak tespit edilmiştir.

Anahtar kelimeler: Stearik Asit, Palmitik Asit, Grafit Nano Parçacık, Nano Parçacık, Faz Değiştiren Maddeler.

\section{Determination of the Thermal Properties of Nano Doped Stearic Acid and Palmitic Acid as Phase Change Material}

\begin{abstract}
Phase Change Materials (PCM) are widely used in engineering applications on heat storage system nowadays. In order to improvement heat storage systems, the choice of Phase Change Materials plays an important role in addition to the heat transfer mechanism. The nanoparticle addition in Phase Change Materials has a significant effect on the improvement of the thermophysical properties. In this study, $1 \%, 3 \%, 5 \%, 10 \%$ by weight Graphite nano particles were added to the Stearic Acid and Palmitic Acid chemicals which are of Phase Change Materials. The thermophysical properties of the prepared mixtures were determined. The homogeneous mixtures, the increase in thermal conductivity values of pure stearic acid and palmitic acid, and a decrease in latent heat were observed. The highest thermal conductivity increase is determined as $89 \%$ in the stearic acid-5\% graphite mixture and $64 \%$ in the Palmitic acid-10\% graphite mixture.
\end{abstract}

Key words: Stearic Acid, Palmitic Acid, Graphite Nano Particles, Nano Particle, Phase Change Material.

\section{Giriş}

Günümüzde artan enerji talebi yenilenebilir enerji kaynakları ve enerji depolama tekniklerinin önemini arttırmaktadır. Enerji üretimi, genel olarak fosil yakıtlarla karşılanmaktadır. Ancak fosil yakıtların yanması sonucu ortaya çıkan $\mathrm{CO}_{2}$ gazı küresel ısınmanın gerekçesi olarak görülmektedir [1]. Bu amaçla, yeni ve yenilenebilir enerji kaynakları ile etkin ve ucuz 1sı depolama sistemlerinin geliştirilmesine yönelik yoğun tetkikler devam ettirilmektedir.

Uygun enerji depolama tekniklerinden biri olan Faz Değiştiren Maddeler (FDM), yıllardan beri çeşitli 1sıl sistemlerde, depolama materyali olarak kullanılmaktadır. Bu maddeler, faz değişimi sırasında çevresinden aldığı veya verdiği 1sıyı, gizli 1sı olarak depolamaktadırlar [2,3]. Ayrıca FDM yenilenebilir enerji kaynakları içerisinde en etkili olanlardan biridir. Bunun nedeni, FDM'in geniş bir uygulama alanına sahip olmasıdır. Bir enerji depolama sisteminin verimli kullanımını sağlamanın en temel gereksinimlerinden biri; belirli bir sürede mümkün olan en fazla enerjiyi depolamaktır. Diğer bir deyişle, enerjinin fazla olduğu bir zamanda enerjiyi depolayarak ihtiyaç duyulduğu zaman kullanıma sunabilmektir [4]. FDM düşük erime/katılaşma sıcaklığına ve yüksek enerji depolama özelliklerine sahiptir. Faz değişim işlemi tersinir olarak gerçekleşir. Endotermik (1sı alan) ve ekzotermik

\footnotetext{
* Sorumlu yazar: tguregen @ gmail.com Yazarların ORCID Numaras1: ${ }^{1}$ 0000-0003-1121-3039, ${ }^{2}$ 0000-0002-5328-2983, ${ }^{3}$ 0000-0002-01376988
} 
(1S1 veren) FDM'ler bu süreçlerde faz değişimine uğrar. Bir madde faz değişim sıcaklığına ulaştı̆̆ zaman erimeye başlar ve bu işlem sırasında sıcaklık sabit kalır. Madde erime esnasında enerjiyi gizli 1sı olarak depolar [5].

Son yıllarda araştırmacılar, FDM'lerin termofiziksel özelliklerini arttırmaya yönelik çalışmalar yapmaktadırlar. Konu ile ilgili yapılan çeşitli sayısal çalışmalar mevcuttur [6,7]. Ayrıca deneysel çalışmalarda iki ya da daha fazla FDM'yi belirli oranlarda karıştırarak, termofiziksel özellikleri daha iyi olan FDM'ler elde etmişlerdir [8]. FDM'lere ısıl iletkenlikleri yüksek olan Bakır Oksit, Alüminyum Oksit, Grafit, Karbon nanotüp vb. nano parçacıklar katılarak, FDM'lerin 1sıl iletkenliğinin arttırılmasına yönelik çalışmalar gerçekleştirmişlerdir. Yapılan bu çalışmalarda FDM'ler farklı alanlara uygulanmıştır. Sarı Palmitik asit, Miristik asit, Stearik asit, Laurik asit gibi farklı FDM'leri kullanarak bu asitlerin gizli 1sı ve erime sıcaklıklarını Diferansiyel Taramalı Kalorimetre (DSC) cihazı ile belirlemiştir [9]. Feldman vd., farklı yağ asidi karışımları hazırlayarak, bunların ısı depolama özelliklerini incelemiş ve yağ asitlerinin alan ssıtma için FDM olarak kullanılabileceğini belirtmiştir [10]. Nazir vd., gizli 1sı depolama sistemleri için Stearik asit, Palmitik asit, Laurik asit ve Mistik asit kullanarak ötektik karışımlar hazırlamışlardır. Hazırlanan kompozitlerin termofiziksel özellikleri DSC ile belirlemişlerdir [11]. Cedeno vd., DSC cihazı ile saf yağ asitleri Oleik asit, Stearik asit, Palmitik asit ve bunların ikili üçlü karışımlarını hazırlamışlardır. Erime sıcaklıkları ve gizli 1sı gibi ısıl özellikleri ile ilgili çalışma yapmışlardır [12]. Gürtürk, Elazığ ilinde ve güneş ışınımının düşük olduğu Kasım ayında, sıcak su tankının, sıcak su ve yalıtım malzemesi arasına FDM'nin bırakılacağı bir depo yaparak, bu depoya, iki farklı saf FDM'nin karışımı ile elde edilen ötektik FDM eklenmiştir. Sistemin FDM'li ve FDM' siz olarak enerji analizlerini yapmıştır [13]. Koca vd, düz plakalı güneş kollektöründe gizli ısı depolama sistemi için FDM kullanarak, enerji ve ekserji analizlerini yapmışlardır. Ekim ayında yapmış oldukları analizlerin ortalama net enerjisinin ve ekserjisinin verimlerinin sırasıyla $\% 45$ ve \%2,2 olduğunu belirtmişlerdir [14]. Literatürde, FDM'nin ısıl özelliklerinin belirlenmesi için yapılan çalışmaların yanı sıra, FDM'nin ısıl özelliklerini iyileştirmek için yapılan çalışmalarda mevcuttur.

Khodadadi ve Hosseinizadeh, nano parçacık katkılı FDM'nin incelendiği bir araştırma sunmuşlardır. Elde edilen Nano Katkılı Faz Değiștiren Maddelerin (NKFDM), temel malzemelerle kıyaslandığında gelişmiş 1Sıl iletkenlik özelliği sergilediğini göstermişlerdir [15]. Ma vd., Stearik asit ve Benzamid'in ikili karışımlarını hazırlamışlardır. Düşük ısıl iletkenliğe sahip ikili karışıma ağırlıkça \%12 geniş̧letilmiş Grafit (EG) ekleyerek 1sıl iletkenliğinin arttırıldığ gözlemlenmiştir [16]. Xia vd., \%0 ile \%10 arasında değişen EG kütle oranı ile parafin maddesinin farklı oranlarda hazırlanması ve bu kompozitlerin ısıl karakteristikliği üzerine çalışma yapmıșlardır [17]. Şahan ve Paksoy, 1sıl enerji depolamada kullanılan FDM'lere ısıl özelliklerinin iyileştirilmesi amacıyla nano Magnetit (Fe3O4) ve Karbon nanotüp eklentisi yapmışlardır. FDM olarak tercih edilen parafinin nano kompozitleri hazırlanarak karakterizasyonu yapmış ve ısıl özelliklerini araştırmışlardır [18]. Taşkıran, 1sıl iletkenlikleri yüksek olan nano parçacıkları, 1sıl iletkenlikleri düşük olan ötektik FDM içerisine ekleyerek, NKFDM hazırlayarak silindirik bir depo içerinde erime katılaşma süreçlerini incelemiştir. Erime ve katılaşma zamanının NKFDM'nin ötektik FDM'ye göre azaldığını belirtmiştir [5]. Lin vd., Palmitik asit ve Polivinil butiral kompozitlerine \%3, \%5 ve $\% 7$ oranlarında genişletilmiş Grafit eklemişlerdir. Bu kompozitlerin 1sıl iletkenliklerini, entalpi değerlerini, kimyasal ve kristal yapılarını incelemişlerdir [19].

$\mathrm{Bu}$ çalışmada Stearik asit ve Palmitik asit FDM'lerine belirli oranlarda (\%1, \%3, \%5, \%10) grafit nano parçacı̆̆ı eklenerek gizli 1sı, erime noktası ve 1sıl iletkenlik gibi termofiziksel özellikleri belirlenmiştir.

\section{Materyal Metod}

Çalışma iki aşamalı olarak gerçekleştirilmiştir. Bunlar;

$\checkmark$ Nano parçacık katkılı homojen karışımların hazırlanması,

$\checkmark$ Hazırlanan karışımların bazı termofiziksel özelliklerinin belirlenmesi şeklindedir.

Deneysel çalışmada, \%99 saflıkta Stearik Asit $\left(\mathrm{C}_{17} \mathrm{H}_{35} \mathrm{COOH}\right)$ ve Palmitik Asit $\left(\mathrm{C}_{16} \mathrm{H}_{32} \mathrm{O}_{2}\right)$ organik FDM'ler MERCK firmasından temin edilmiştir. Kullanılan malzemelerin bilinen fiziksel özellikleri Tablo 1'de verilmiştir.

Tablo 1. Malzemelerin fiziksel özellikleri [20].

\begin{tabular}{cccc}
\hline Malzemeler & $\begin{array}{c}\text { Moleküler Ăğırlık } \\
(\mathbf{g} / \mathbf{m o l})\end{array}$ & Yoğunluk $\left(\mathbf{g} / \mathbf{c m}^{\mathbf{3}}\right)$ & $\begin{array}{c}\text { Erime Noktası } \\
\left({ }^{\circ} \mathbf{C}\right)\end{array}$ \\
\hline Stearik Asit & 284,48 & 0,845 & $67-72$ \\
Palmitik Asit & 256,42 & 0,852 & $61-63$ \\
Grafit & 348,48 & 2,2 & - \\
\hline
\end{tabular}


Deneylerin doğru șekilde yapılabilmesi için 1sıl kararlılığa sahip olması gerekmektedir. Bu nedenle, karışımlar hazırlanırken malzemeleri homojen hale getirmek için manyetik karıştırıcı kullanılmıştır. Manyetik karıştırıcının sıcaklık parametresi, karıştırılacak malzemenin erime noktası ve parlama noktası dikkate alınarak belirlenmiştir. Bu kimyasal malzemelerin erime sıcaklığının üzerinde bir sıcaklık değeri belirlenerek, hazırlanan karışımların faz değiştirerek homojen olarak karıştırılması amaçlanmıştır. Saf malzemelere belirli ağırlık oranlarında Grafit nano parçacık eklenerek hazırlanan NKFDM'ler, manyetik karıştırıcı ile malzeme homojen olana kadar dokuz saat $85^{\circ} \mathrm{C}$ 'de karıştırılmıştır. Şekil 1'de karışımların hazırlanması gösterilmektedir.
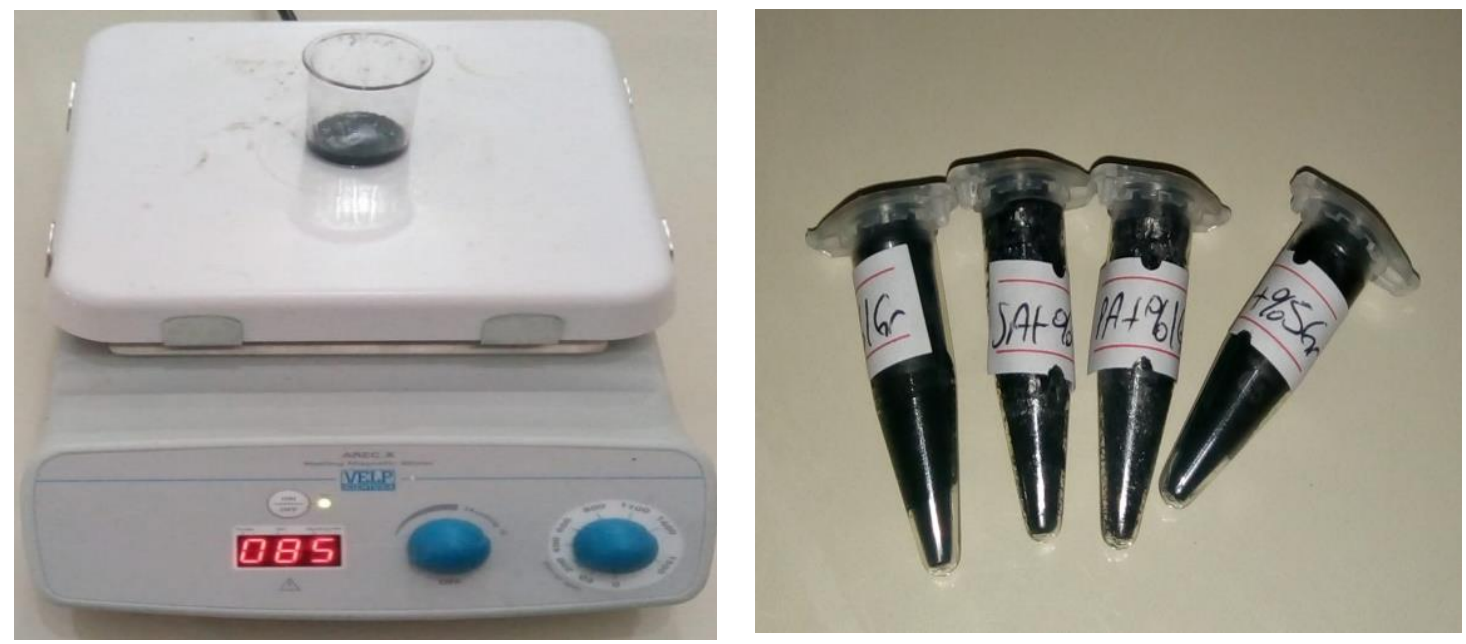

Şekil 1. Karışımların manyetik karıştırıcıda hazırlanması.

Hazırlanan numunelerin erime noktası ve gizli 1sı değerlerinin belirlenebilmesi için HITACHI 7010 Diferansiyel Taramalı Kalorimetre (DSC) kullanılmıştır. DSC, numune 1sıtılırken, soğutulurken ya da sabit bir sıcaklıkta tutulurken soğurulan ya da salıverilen enerji miktarını ölçer. Bu teknik ile referans ve numuneden gelen ya da uzaklaşan 1sı fark1, sıcaklığa veya zamana bağlı olarak gösterilmektedir [21]. Numunelerin, azot atmosferinde $10^{\circ} \mathrm{C} /$ dak ısıtma hızıyla $15^{\circ} \mathrm{C}$ 'den başlayarak $90^{\circ} \mathrm{C}$ 'ye kadar 1sıtılarak, DSC eğrileri alınmıştır. DSC eğrileri sonucunda TA7000 standart analiz programı yardımıyla erime sıcaklığı ve gizli 1sı değeri belirlenmiştir. NKFDM'lerin 1sıl iletkenlik değerlerinin belirlenmesinde KD2-Pro 1sıl özellik analiz cihazı kullanılmıştır. Homojen karışımlar steril plastik tüpler içine konularak cihazın SH-1 iğnesi ile ölçümler alınmıştır.

\section{Bulgular}

$72^{\circ} \mathrm{C}$ 'de katı-sıvı faz geçişine sahip Stearik asit ve $61-62,5^{\circ} \mathrm{C}$ de katı-sıvı faz geçişine sahip Palmitik asit ile deneysel bir çalışma yapılmıştır. Bu çalışmada, asitlerin ısıl özelliklerini geliştirmek için ağırlıkça $\% 1, \% 3, \% 5$ ve \%10 kütle oranında grafit nano parçacıkları eklenmiştir. Palmitik asit, Stearik asit ve Grafit nano parçacığının çalışma için kullanılan miktarları Tablo 2'de verilmiştir.

Tablo 2. Karışımlardaki maddelerin kütlece değerleri

\begin{tabular}{|c|c|c|c|}
\hline $\begin{array}{l}\text { Kütlece Grafit } \\
\text { Oranları (\%) }\end{array}$ & $\begin{array}{c}\text { Palmitik Asit } \\
\text { (gr) }\end{array}$ & $\begin{array}{c}\text { Stearik Asit } \\
\text { (gr) }\end{array}$ & $\begin{array}{c}\text { Grafit } \\
\text { (gr) }\end{array}$ \\
\hline 1 & 1,2 & 1,2 & 0,024 \\
\hline 3 & 1,2 & 1,2 & 0,072 \\
\hline 5 & 1,2 & 1,2 & 0,12 \\
\hline 10 & 1,2 & 1,2 & 0,24 \\
\hline
\end{tabular}

Kullanılan Palmitik asit, Stearik asit ve Grafit nano parçacı̆̆ının 1sıl iletkenlik değerleri Tablo 3'de yer almaktadır. 
Tablo 3. Maddelerin 1sıl iletkenlik değerleri.

\begin{tabular}{llll}
\hline Malzemeler & Ölçüm & $\begin{array}{l}\text { Isll } \\
\text { Illetkenlik } \\
(\mathbf{W} / \mathbf{m K})\end{array}$ & $\begin{array}{l}\text { Sıcaklık } \\
\left({ }^{\circ} \mathbf{C}\right)\end{array}$ \\
\hline Stearik asit & 1. Ölçüm & 0,148 & 26,75 \\
& 2. Ölçüm & 0,150 & 27,12 \\
& 3. Ölçüm & 0,153 & 32,66 \\
& Ortalama & $\mathbf{0 , 1 5 0}$ & \\
Palmitik asit & 1. Ölçüm & 0,172 & 30,91 \\
& 2. Ölçüm & 0,157 & 33,73 \\
& 3. Ölçüm & 0,165 & 34,90 \\
& Ortalama & $\mathbf{0 , 1 6 4}$ & \\
& 1. Ölçüm & 0,143 & 25,45 \\
& 2. Ölçüm & 0,147 & 24,96 \\
& 3. Ölçüm & 0,149 & 25,26 \\
& Ortalama & $\mathbf{0 , 1 4 6}$ & \\
\hline
\end{tabular}

Bu kimyasal malzemelerinin saf hallerinin isıl iletkenlik değerleri ölçülmüş olup, sirasıyla 0,150, 0,164, 0,146 W/mK olarak bulunmuştur. Stearik Asit ve nano parçacık katkısı ile hazırlanan NKFDM'lerin KD2 Pro ile elde edilen 1sıl iletkenlik değerleri Tablo 4'de verilmiştir.

Tablo 4. NKFDM (Stearik asit - Grafit) 1sıl iletkenlik değerleri.

\begin{tabular}{llll}
\hline NKFDM & Ölçüm & $\begin{array}{l}\text { Isıl İletkenlik } \\
(\mathbf{W} / \mathbf{m K})\end{array}$ & $\begin{array}{l}\text { Sicaklık } \\
\left({ }^{\circ} \mathbf{C}\right)\end{array}$ \\
\hline Stearik & 1. Ölçüm & 0,191 & 28,29 \\
Asit- \%1 & 2. Ölçüm & 0,190 & 32,10 \\
Grafit & 3. Ölçüm & 0,189 & 35,50 \\
& Ortalama & $\mathbf{0 , 1 9 0}$ & \\
& & & \\
Stearik & 1. Ölçüm & 0,202 & 27,13 \\
Asit- \%3 & 2. Ölçüm & 0,189 & 32,34 \\
Grafit & 3. Ölçüm & 0,188 & 34,60 \\
& Ortalama & $\mathbf{0 , 1 9 3}$ & \\
Stearik & 1. Ölçüm & 0,298 & 26,00 \\
Asit- \%5 & 2. Ölçüm & 0,285 & 29,86 \\
Grafit & 3. Ölçüm & 0,271 & 28,41 \\
& Ortalama & $\mathbf{0 , 2 8 4}$ & \\
Stearik & 1. Ölçüm & 0,255 & 27,95 \\
Asit- \%10 & 2. Ölçüm & 0,255 & 29,42 \\
Grafit & 3. Ölçüm & 0,259 & 29,35 \\
& Ortalama & $\mathbf{0 , 2 5 6}$ & \\
\hline
\end{tabular}

Tablo 4'de verilen sonuçlar göz önüne alındığında Stearik aside \%5 Grafit nano parçacığı eklentisi yapıldığında $1 s 1$ iletkenlik değerinin daha yüksek olduğu görülmektedir. Yapılan çalışmaya göre nano parçacık katkısının FDM'nin saf haline göre 1sıl iletkenlik değerini arttırdığı gözlemlenmektedir.

Tablo 5'de Palmitik asit ve Grafit nano parçacık katkısı ile hazırlanan NKFDM'lerin KD2 Pro ile elde edilen 1sıl iletkenlik değerleri verilmektedir. Tablo 5'de ki sonuçlara göre Palmitik asit \%10 Grafit nano parçacı̆̆ eklentisi yapıldığında 1sıl iletkenlik değerinin diğer numune sonuçları incelendiğinde daha yüksek olduğu görülmektedir. Bu çalışmada da Stearik asit ile hazırlanan NKFDM'lerde olduğu gibi, nano parçacık katkısının FDM'nin saf haline göre 1sıl iletkenlik değerini arttırdığı gözlemlenmektedir. 
Tablo 5. NKFDM (Palmitik asit - Grafit) 1sıl iletkenlik değerleri.

\begin{tabular}{llll}
\hline NKFDM & Ölçüm & Isıl İletkenlik $(\mathbf{W} / \mathbf{m K})$ & Sıcaklık $\left.\mathbf{}^{\circ} \mathbf{C}\right)$ \\
\hline Palmitik & 1. Ölçüm & 0,185 & 29,91 \\
Asit- \%1 & 2. Ölçüm & 0,186 & 31,69 \\
Grafit & 3. Ölçüm & 0,183 & 33,02 \\
& Ortalama & $\mathbf{0 , 1 8 4}$ & \\
\hline Palmitik & 1. Ölçüm & 0,221 & 30,75 \\
Asit- \%3 & 2. Ölçüm & 0,202 & 32,26 \\
Grafit & 3. Ölçüm & 0,208 & 33,55 \\
& Ortalama & $\mathbf{0 , 2 1 0}$ & 32,94 \\
\hline Palmitik & 1. Ölçüm & 0,200 & 33,23 \\
Asit- \%5 & 2. Ölçüm & 0,197 & 33,74 \\
Grafit & 3. Ölçüm & 0,198 & 31,84 \\
& Ortalama & $\mathbf{0 , 1 9 8}$ & 32,47 \\
\hline Palmitik & 1. Ölçüm & 0,282 & 32,70 \\
Asit- \%10 & 2. Ölçüm & 0,271 & \\
Grafit & 3. Ölçüm & 0,259 &
\end{tabular}

Şekil 2'de Stearik asit-Grafit karışımlarının, Şekil 3' te ise Palmitik asit-Grafit karışımlarının DSC analizleri yer almaktadir.

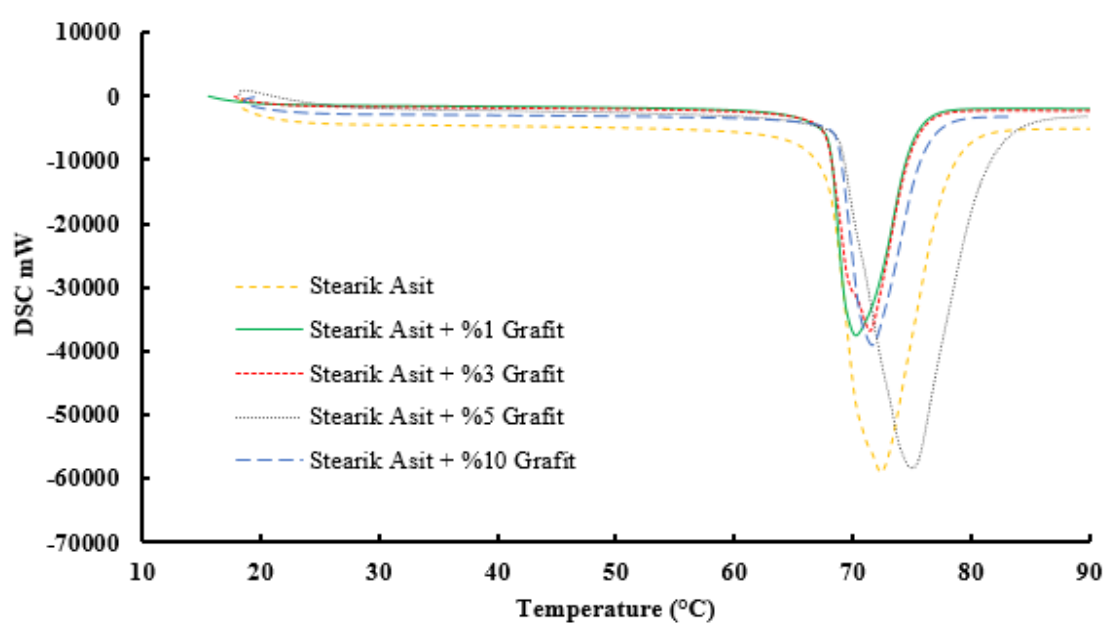

Şekil 2. Stearik asit- Grafit karışımlarının DSC grafikleri.

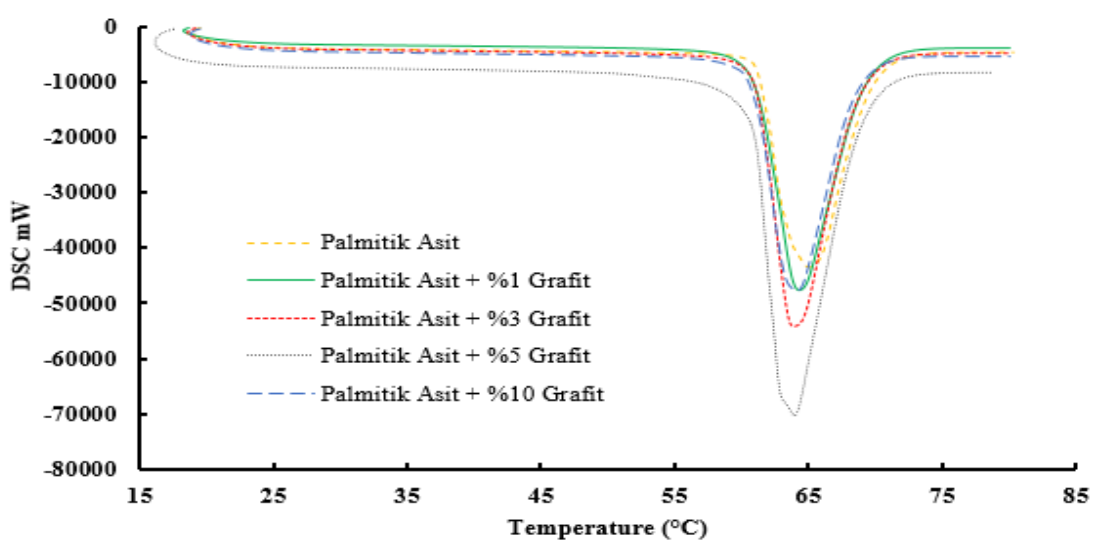

Şekil 3. Palmitik asit- Grafit karışımlarının DSC grafikleri. 
Saf Stearik asit, nano katkılı karışımlara göre daha fazla oranda enerjiyi absorbe etmiștir. Ayrıca erime başlangıç-bitiş sıcaklığı arasında farklılıklar görülmemiştir. Ancak \%5 nano Grafit katkılı Stearik asitte bu durumun farklı olduğu görülmektedir. Palmitik asitte ise nano katkının erime başlangıç bitiş sıcaklığg arasında etkili olmadığı bulunmuştur. Palmitik asite yapılan \%5'lik nano katkının daha fazla enerjiyi absorbe ettiği görülmüştür. \%5'lik nano katkının asit bazlı FDM grubunda enerji absorbe oranını değiştirdiği belirlenmiştir. DSC sonuçları incelendiğinde NKFDM'lerden elde edilen veriler Tablo 6'da yer almaktadır.

Tablo 6. NKFDM'lerin DSC ile elde edilen termofiziksel değerleri.

\begin{tabular}{lcc}
\hline NKFDM & Gizli Isı $(\mathbf{J} / \mathbf{g})$ & Erime Sıcaklığı $\left({ }^{\circ} \mathbf{C}\right)$ \\
\hline Stearik asit & $\mathbf{2 2 6}$ & $\mathbf{7 2 , 4}$ \\
Stearik asit - \%1 Grafit & 226 & 70,21 \\
Stearik asit - \%3 Grafit & 211 & 71,6 \\
Stearik asit - \%5 Grafit & 202 & 74,9 \\
Stearik asit - \%10 Grafit & 192 & 71,74 \\
Palmitik asit & $\mathbf{2 2 2}$ & $\mathbf{6 5 , 0 7}$ \\
Palmitik asit - \%1 Grafit & 204 & 64,37 \\
Palmitik asit -\%3 Grafit & 210 & 63,95 \\
Palmitik asit - \%5 Grafit & 220 & 63,88 \\
Palmitik asit - \%10 Grafit & 197 & 64,17 \\
\hline
\end{tabular}

NKFDM'lerin gizli 1Sı ve erime sıcaklığı değerlerine göre Stearik asit için \%1 Grafit katkılı, Palmitik asit için ise $\% 5$ Grafit katkılı hallerinin gizli 1sı depolama kapasitesinin daha iyi sonuç verdiği görülmektedir. Tablo 7'de ısıl iletkenlik değerlerinin oransal olarak karşılaştırılması yapılmıştır.

Tablo 7. Isıl iletkenliklerin oransal olarak karşılaştırılması.

\begin{tabular}{cll}
\hline Nano oranları & Stearik Asit & Palmitik Asit \\
\hline$\% 0$ & 0.150 & 0,164 \\
$\% 1$ & $0,190(+\% 26)$ & $0,184(+\% 12)$ \\
$\% 3$ & $0,193(+\% 28)$ & $0,210(+\% 28)$ \\
$\% 5$ & $0,284(+\% 89)$ & $0,198(+\% 20)$ \\
$\% 10$ & $0,256(+\% 70)$ & $0,270(+\% 64)$ \\
\hline
\end{tabular}

Nano katkı eklendikçe 1sıl iletkenliğin arttığı gözlemlenmiştir. Optimum değer için nano katkı oranının oransal değeri önemlidir.

\section{Sonuçlar}

Yapılan çalışmada öncelikle saf Stearik asit ve Palmitik asit FDM'lerinin erime sıcaklığı gizli 1sı depolama kapasitesi, ısıl iletkenlik gibi termofiziksel özellikleri belirlenmiştir. Bu FDM'lere farklı kütle oranlarında (\%1, \%3, \%5, \%10) Grafit nano parçacık eklenerek, termofiziksel özeliklerindeki değişimler incelenmiştir.

Deneysel bulgular neticesinde nano parçacık eklentisinin FDM'lerin 1sıl iletkenlik değerlerinin saf hallerine göre arttırdığı gözlemlenmiştir. Yapılan nano parçacık katkısı ile birlikte erime sıcaklığı değerlerinin Stearik asit için 70,21 ile $74,9^{\circ} \mathrm{C}$, Palmitik asit için ise 63,88 ile $64,37^{\circ} \mathrm{C}$ arasında değiştiği belirlenmiştir. Bunlara ek olarak gizli 1sı depolama kapasitesinin Stearik asitte, nano parçacık katkısının kütlesel olarak artan oranlarda yapılması durumunda azaldığ 1 , Palmitik asitte, kütlece $\% 1, \% 3, \% 10$ oranında yapılan nano parçacık eklentisinde azaldığı, $\% 5$ 'te ise saf halindeki gizli 1sı depolama kapasitesine yakın olduğu sonucu elde edilmiştir.

Elde edilen Nano Katkılı Faz Değiştiren Maddelerin, saf halleriyle kıyaslandığında gelişmiş ısıl iletkenlik özelliği sergilediği görülmektedir. Stearik asit için \%5, Palmitik asit için \%10 Grafit nano parçacığı eklendiğinde 1sıl iletkenlik değerlerinin, diğer nano katkı oranlarına göre daha başarılı sonuçlar verdiği görülmüştür. Erime sıcaklığını başlama ve bitiş değerleri açısından Stearik asitin nano katkısıyla daha dar bir aralıkta gerçekleştiği görülmüştür. Bu parametrelere göre değerlendirildiğinde uygulama yerine uygun NKFDM'nin seçilmesinde elde edilen bu bulguların faydalı olacağı düşünülmektedir. 


\section{Kaynaklar}

[1] Yılmazoğlu, M.Z. Isı depolama yöntemleri ve binalarda uygulanması, Politeknik Dergisi,2010; 13: 33-42.

[2] Konuklu, Y., Ersoy, O., Paksoy, H.Ö., Evcimen, S., Çelik, S. ve Toraman, Ö.Y. Termal enerji depolama materyali olarak diyatomit/faz değiştiren madde kompozitlerinin üretilmesi, Ömer Halisdemir Üniversitesi Mühendislik Bilimleri Dergisi, 2017; 6(1): 238-243.

[3] Sharma, S.D. and Sagara, K. Latent heat storage materials and system: A review, International Journal of Green Energy, 2005; 2: 1-56.

[4] Dincer, İ. and Rosen, M.A. Thermal energy storage systems and applications. Canada: Wiley Publication, 2011.

[5] Taşkıran, A. Nano boyutlu parçacık katkılı yeni nesil faz değiştiren maddelerin deneysel olarak incelenmesi. Yüksel Lisans Tezi, Fırat Üniversitesi Fen Bilimleri Enstitüsü, Elazı̆̆, 2013.

[6] Koca, A., Yamaç, H.İ. and Üregen, T.G. Computational Fluid Dynamic Analysis of Phase Change Material Heat Storage Tank Have Spiral Coil Pipe. 1st International Engineering and Technology Symposium; 3-5 May 2018 , Batman: pp. 3437.

[7] Yamaç, H.İ. and Koca, A. Numerical Analysis on Phase Change Materials Used in Thermal Energy Storage Tank. International Conference on Innovative Engineering Applications, 20-22 September 2018, Sivas: pp. 841-847.

[8] El-Bassuoni, A-M.A., Tayep, A.M., Helwa, N.H., and Fatyh, A.M. Modification of urea-sodium acetate trihydrate mixture for solar energy storage, Renewable Energy, 2003; 28: pp. 1629-1643.

[9] Sar1, A. (2003). Thermal reliability test of some fatty acids as PCMs used for solar thermal latent heat storage applications, Energy Conversion \& Management, 44(14): 2277-2287.

[10] Feldman, D., Shapiro M.M., and Banu D. Organic phase change materials for thermal energy storage, Solar Energy Materials, 1986; 13(1): pp. 1-10.

[11] Nazir, H., Batool, M., Ali, M. and Kannan, A.M. Fatty acids based eutectic phase change system for thermal energy storage applications, Applied Thermal Engineering, 2018; 142: pp. 466-475.

[12] 12. Cedeno, F.O., Prieto, M.M, Espina, A. and Gracia, J.R. Measurements of temperature and melting heat of some pure fatty acids and their binary and ternary mixtures by DSC, Thermochimica Acta, 2001; 369(1-2): pp. 39-50.

[13] Gürtürk, M., Koca, A., Öztop, H.F., Varol, Y. and Şekerci, M. Energy and exergy analysis of a heat storage tank with a novel eutectic phase change material layer of a solar heater system, International Journal of Green Energy, 2017; 14(12): pp. 1073-1080.

[14] Koca, A., Öztop, H.F., Koyun, T. and Varol, Y. Energy and exergy analysis of a latent heat storage system with phase change material for a solar collector, Renewable Energy, 2008; 33, pp. 567-574.

[15] Khodadadi, J.M. and Hosseinizadeh, S.F. Nanoparticle-enhanced phase change materials (NEPCM) with great potential for improved thermal energy storage, International Communications in Heat and Mass Transfer, 2007; 34(5): pp. 534543.

[16] Ma, G., Sun, J., Zhang, Y., Jing, Y. and Jia, Y. Preparation and thermal properties of stearic acid-benzamide eutectic mixture/expanded graphite composites as phase change materials for thermal energy storage, Powder Technology, 2019; 342: pp. 131-140.

[17] Xia, L., Zhang, P. and Wang, R.Z. Preparation and thermal characterization of expanded graphite/paraffin composite phase change material, Carbon, 2010; 48(9): pp. 38-48.

[18] Şahan, N. ve Paksoy, H.Ö. Faz değiştiren maddelerin nano malzemelerle kullanımının araştırılması, Çukurova Üniversitesi Fen ve Mühendislik Bilimleri Dergisi, 2013; 29(4): 24-30.

[19] Lin, Y., Zhu, C., Alva, G. and Fang, G. Palmitic acid/polyvinyl butyral/expanded graphite composites as formstable phase change materials for solar thermal energy storage, Applied Energy, 2018; 228: pp. 1801-1809.

[20] http://www.merckmillipore.com, 12 Kasim 2018.

[21] Beşergil, B., Enstrümantal Analiz Temel İlkeler. Ankara, Türkiye: Gazi Kitabevi: 2015. 